\title{
The Effects of 'Reciprocal Teaching of Reading' and 'Cooperative Integrated Reading and Composition' on the Reading Comprehension of Iranian EFL Intermediate Students
}

\author{
Zahra Kamdideh \\ Department of English Language and Literature, Ayatollah Amoli Branch, Islamic Azad University, Amol, Iran \\ Reza Vaseghi \\ Department of English Language and Literature, Ayatollah Amoli Branch, Islamic Azad University, Amol, Iran \\ Saeedeh Talatifard \\ Department of English Language and Literature, Ayatollah Amoli Branch, Islamic Azad University, Amol, Iran
}

\begin{abstract}
The present study investigated the effects of Reciprocal Teaching of Reading (RTR) and Cooperative Integrated Reading and Composition (CIRC) on the reading comprehension of Iranian EFL intermediate students. After administering the Preliminary English Test (PET) to a total population of 53, this researcher selected an almost homogeneous group of 42 Iranian intermediate students and randomly assigned them to two groups of CIRC and RTR techniques - 21 students per group. Based on their scores, both classes were divided into 7 almost heterogeneous teams - three members each. Both groups received the same instruction for five weeks and the course lasted for 15 sessions of 90 minutes. Whereas the RTR group experienced their reading course via RTR, which emphasizes explicit teaching of reading strategies, the other group experienced their reading course through CIRC. Upon the end of the treatment, a PET was administered to both groups as post-test. The scores of the post-test were compared with those of the on pretest. Results showed that RTR had a more significant effect on the improvement of reading comprehension of the participants. The factors that led to the results of the study and the pedagogical implications for EFL teachers, syllabus designers and materials developers are discussed. In addition, she suggests recommendations for further research.
\end{abstract}

Index Terms-reciprocal teaching of reading, cooperative integrated reading and composition, reading comprehension, intermediate EFL learners

\section{INTRODUCTION}

There is no doubt today in the idea that reading is one of the most important skills for educational and professional success. Due to the fact that English is the main medium of communication of information and science throughout the world, the reading skill "in English has received priority among other objectives of English language teaching" (Salari \& Hosseini, 2019, p. 489). That is the reason that Farhadi (1998) believes that improving reading skills is a top priority in many countries. Despite the fact that the main goal of English Language Teaching, in Iran, is improving reading ability of students, ELT has not been a success in our country hitherto (Hosseini, 2012). It is in such a context that the focus of language teachers is shifting towards Constructivists' methods and approaches to language teaching.

Concurrent with the popularity of Constructivists' methods and approaches to teaching among teachers, the research results have also shown that particularly Cooperative Learning (CL) techniques enhance language learning more than the individualized or competitive methods. CL "is the instructional use of small groups so students work together small groups so students work together to maximize their own and each other's learning" (Johnson, Johnson, \& Smith, 1998, p. 2). There are, however, different ways of group work or CL that can be applied by classroom teachers. This means that, CL learning is a general term that refers to a number of instructional techniques that focus on group work. RTR and CIRC are among the most popular techniques of CL. Learners engage in interaction in small groups to cooperate with each other, which helps them "achieve individual and common goals" (Gurk \& Mall-Amiri, 2016, p. 40). The outcomes of this cooperation will eventually lead to individual and group interests for achieving goals.

Cooperative learning enjoys support and gets credit from some theories of language learning. Davis (1999) states that the role of community is a pivotal one "in the process of making meaning" (p.5). According to him, CL provides the opportunity for learners to experience interacting with others who are at different levels of mastery to which they are, and peers provide scaffold for the learning of one another and so contribute to their Zone of Proximal Development (ZPD).

As researchers like Momtaz and Garner (2010) argue, despite a considerable body of studies carried out in the West 
on how effective cooperative learning can be, there is no enough research in how much they can be effective in nonWestern contexts. This fact is also true about EFL settings in countries like Iran. It is in such a context that the researchers selected RTR to be compared with CIRC. This study focused on teaching reading comprehension through these techniques to find out which of them would have a more significant effect on the EFL intermediate learners' reading comprehension. The researchers selected these techniques because she is convinced that the selected techniques are more effective than the others in the realm of CL for improving reading abilities of students.

Therefore, the following question was posed to further guide the study towards finding an answer:

Q: Is there any significant difference between the effects of RTR and CIRC on the intermediate EFL learners' reading performance?

\section{A. Reciprocal Teaching of Reading}

Originally Palinscar and Brown (1985) at the University of Illinois at Urbana-Champaign coordinated their efforts to launch RTR as a special program to suit poo readers who had not profited from traditional reading instructional methods in early levels of education. One major characteristic of this technique of CL refers to the emphasis it lays on strategy training in reading courses, in environments which appreciate the significance of social scaffolding in learning activities. For the purpose of joint understanding of a text, participants, in their heterogeneous groups, are mostly practiced in four specific reading comprehension strategies namely predicting, summarizing, questioning, and clarifying.

The significance of predicting, especially in reading classes, is believed to lie in its contribution to intensifying students' focus on what they are reading, in order to see whether their predictions come true. This strategy engages students in learning because they have to concentrate on the content in order to evaluate their predictions. Summarizing is likewise assumed to encourage class participants to integrate what they have learnt. In other words, in order to summarize or reproduce the text, students have to implement their lexicon and syntax which they have acquired through listening, reading, and speaking. The philosophy behind the emphasis on generating questions is that learning to generate questions in lieu of only responding to teacher's questions challenges deeper levels of students' cognition. And finally, the belief is that clarifying promotes comprehension monitoring of interlocutors, which, in turn, increases their meta-cognition abilities.

\section{B. Cooperative Integrated Reading and Composition}

Slavin (1995) has developed CIRC which is a comprehensive program for teaching reading and writing, and language arts. This technique of CL focuses on simultaneous development of reading and writing skills of participants because it considers them as two inseparable skills. Lesson elements, in this method, incorporate:

1. Introducing the topic and the theme of the text;

2. Introducing the meaning of new words;

3. Reading silently and reading to a partner;

4. Analyzing the text's linguistic features;

5. Summarizing the text, and

6. Practicing word recognition and spelling to the point of mastery.

The focal focus of CIRC is to motivate students through specially structured group work "to improve the skills in comprehending the texts for improving reading and writing skills" (Hadiwinarto \& Novianti, 2015, p. 118). Slavin (2011) suggests the following steps in implementing CIRC technique:

"(1) form groups of four heterogeneous students; (2) teachers give texts related to the learning topic; (3) students cooperate with each other to read and find main idea and give feedbacks to the texts and write them on paper; (4) explain/read the group result; (5) teachers and students make a conclusion together; (6) closing" (As cited in Hadiwinarto \& Novianti, 2015, p. 18).

\section{REVIEW OF LITERATURE}

Some studies have been carried out in the field of reading comprehension and reading strategies, as well as CIRC and RTR techniques. This section will discuss the latest research done in the area to further pave the way for this study.

One of these studies is that of Calderón, Hertz-Lazarowitz, and Slavin (1998) who evaluated the effects of bilingual CIRC on reading, writing and language achievements of Spanish and English in a Spanish bilingual program. They did a comparison of the learners' test scores and found that on in the Spanish test, "second-graders scored significantly better than comparison students in writing and marginally better $(p<.06)$ in reading" (p. 153). They also found that regarding English test, third-grade participants outperformed the other group in reading comprehension. They then argue that third-graders who were in CIRC scored much better than control students on both scales.

Another study that studied the same area of research is that of Gupta and Ahuja (2014) who studied the impact of CIRC on the English reading comprehension of seventh graders. The compared cooperative learning with conventional teaching learning classroom structure using an experimental design by employing 140 students, out of who 70 were chosen for experimental group and 70 for control group. What they found in their study was that the experimental group outperformed the control group. They then state that the CIRC group was significantly better than conventional method of teaching reading in the scores of the learners. 
In their study, Gurk and Mall-Amiri (2016) investigated the effect of cooperative learning activities like Number Heads Together on 90 Intermediate Iranian EFL learners' reading comprehension, and reading strategies. They found that "cooperative learning activities had a significant positive effect on intermediate Iranian EFL learners' reading comprehension, and reading strategies" (p. 33).

In another study, Sittilert (1994) investigated the possible effect of CIRC on EFL learners' reading abilities. He employed 106 EFL learners who had enrolled in a class of reading comprehension in English, and divided them into two groups of experimental and control. In the experimental group, the researcher implemented CIRC as a means of instruction, while the control group was taught using a traditional method that the teacher had developed. His research findings revealed that the experimental group outperformed the control group in reading comprehension posttest when compared to the pretest. Another finding of his research was that the experimental group had a positive attituded towards the technique used in their class.

In 2011, Durukan implemented CIRC in nine $3^{\text {rd }}$ grade classes in rural Ohio with 198 students. Reading subtests of the California Achievement Test were utilized in order to compare results of the study with previous evaluations of CIRC. A multivariate analysis of covariance with univariate follow-up analyses revealed that the "CIRC group outgained the control group on reading comprehension" (103). In addition to this finding, it was revealed that low performers reaped more benefits out of the implication of this strategy when low, middle, and high performers were divided into different groups. Teacher acceptability ratings also indicated positive experiences with CIRC.

In another study, Momtaz and Garner (2010) reported that the effects of cooperative reading in enhancing the reading comprehension ability of university students were salient in their study. Such a finding in relation of effectiveness of CL at the graduate level corroborates those of Hosseini's (2012) $\mathrm{PhD}$ level research study that the average scores of university students in CL were higher than those of students in a traditional teacher-oriented English reading class.

Another study that was carried out by Alfassi (2004), the researcher investigated the effects of RTR on learners' reading comprehension in the English language. To carry out the study, the researcher employed 49 participants who were good at reading comprehension, and assigned them to two groups of experimental (RTR), and control (traditional literacy instruction). Equivalent teachers, who received six hours of training, outlined the material and managed the classes for 20 days. The findings of his research revealed that there was a significant difference between the two groups, with the experimental group outperforming the control group. The researcher then concludes that "the educational benefits of incorporating RTR into the English Language arts curriculum were verified" (p. 171).

In another study, Konpan's (2006) study was aimed at comparing reciprocal teaching with communicative language teaching (CLT) on learners' reading. To carry out the research, the researcher employed 12th-grade Thai students and divided them into two groups of experimental and control. In the experimental group, RTR was used, while in the control group, CLT was employed. Results showed that the experimental group had a significantly better performance of the control group in reading comprehension. Therefore, the superiority of RTR over the communicative language teaching technique was confirmed.

In the same vain, Wisaijorn (2003) conducted an experimental study with only one group to investigate the effectiveness of RTR on reading comprehension of Thai EFL students. The design of his study was a mixed method one, having both quantitative and qualitative designs, which required a test before and another after the treatment. The results of the quantitative part of his study revealed that that "reciprocal teaching improved the students' reading ability" (p. 83).

Finally, Rosenshine and Meister (1994) gathered 16 quantitative research studies that were carried out on higher education settings regarding reciprocal teaching, and conducted a meta-analysis on them. Their study revealed that "reciprocal teaching was most effective for older students as well as those with poor comprehension skills" (p. 479).

This review of the literature revealed that despite the abundance of research on the advantages of CL on reading comprehension compared to other traditional methods, very few research studies have been conducted with the aim of investigating whether there is a significant difference between the effects of RTR and CIRC, especially in the Iranian context wherein English is dealt with as a foreign language. This research study addresses this lacuna in the related literature.

\section{METHOD}

\section{A. Overview}

This study explored if there is any significant difference between the effects of RTR and CIRC on the intermediate EFL students' reading performance.

\section{B. Design of the Study}

This study used a quasi-experimental design in which grouping was carried out randomly. Furthermore, the design of this study was a pretest-posttest design with two experimental groups included. The design is presented in the following figure: 

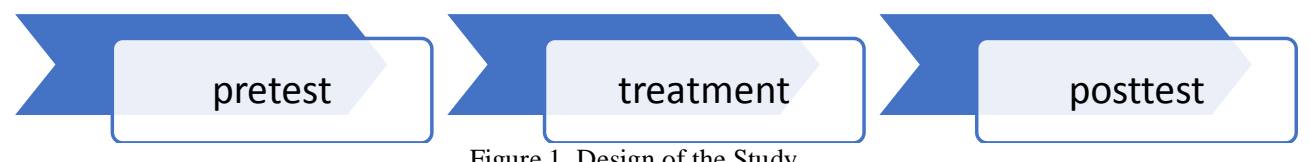

Figure 1. Design of the Study

\section{Participants}

The primary participants of this study were fifty-three intermediate students at Dr Hosseini's Language Institute in Mashhad, Iran. After conducting a the pretest, forty-two were selected as the sample of the research based on their performance in the reading comprehension pretest. The participants of this study were all male, whose ages ranged between 18 to 23. All of the participants were native speakers of Persian. They have studied English for three years hitherto.

\section{Instruments}

To gather the required data for this research study, the following instruments were used.

\section{Preliminary English Test (PET)}

To determine the proficiency level of the participants, the researchers administered a Preliminary English Test (PET), which included four main skills (i.e., reading, writing, listening, and speaking), prior to the start of the treatment. The test consisted of a reading section of 5 parts with 35 reading comprehension questions and a writing section of 3 parts with 8 questions. Learners had 1 hour and 30 minutes to answer the questions, which was divided into two parts of reading and writing, each taking 45 minutes.

Properties like item facility (IF) and item discrimination (ID) were tested. In addition, the test showed a high level of internal consistency, which stood at 0.92 . Furthermore, item analysis suggested that there is no need to remove any item from the final results, therefore, none of the questions were eliminated. The researchers used the General Mark Schemes for writing by Cambridge in order to rate all the writings in this study. The test was rated based on the scale of 0-5.

In addition, an inter-rater reliability was carried out to make sure that the chance of bias and subjectivity between the two raters was low. The test results suggested that based on the criteria of standard deviation, 42 learners were qualified to be employed as the sample of the study. In other words, out of the 53 participants who expressed willingness to take part in this study, 42 scored one unit below and above the standard deviation. After the homogenization, the participants were assigned to two groups of 21 each, with one of them being taught with CIRC and the other with RTR technique. This test was applied to demonstrate the level of the participants and homogenization, and also to check the reading comprehension of the participants of this study before and after the experiment.

\section{Course Book}

The $3^{\text {rd }}$ edition of "ACTIVE 2 skills for reading book", by Neil. J Anderson (2013), was selected for teaching reading comprehension to the target students in this study. A wide variety of texts for reading comprehension consisted this book, including journal entries, websites, personal blogs and questionnaires. The book consisted of 24 chapters embedded in 12 units, with each one having a variety of exercises and activities, such as pre-reading and post-reading activities, each covering different aspects of languages, like grammar, vocabulary and other reading skills and conversation strategies. Out of the 12 units, six of them were selected to be covered within the course of the treatment, which was set at 15 sessions of 90 minutes each. The RTR group received instructions by RTR technique of CL while the other group were taught through CIRC.

\section{E. Procedure}

This research had a pretest-posttest design; therefore, the pretest was considered both as the starting point and the homogenization process, based on which, 42 students were chosen out of the 53 participants who were willing to take part in the study. The homogenization process eliminated those learners who were at the lower parts of the bell curve. Then the selected sample of the participants were randomly assigned to two groups of CIRC and RTR, with 21 students in each of the groups. Then the treatment began and the participants participated in classes with 15 sessions of 90 minutes each.

It is also noteworthy that the researchers made sure that the participants of this study were not informed of the fact that they were being tested on reading comprehension with the two techniques. During the class procedure, groups the learners were assigned to seven groups of three students to carry out the class assignments, with proper classroom arrangement to help them have convenient face-to-face interaction with their peers in their groups. It was also made sure that both groups were in similar class and teaching conditions, including the teacher, timing and curriculum, and the same schedule of instruction. The only thing that was different between the two groups was that in one of them CIRC was used, while in the other one, RTR was used, which focuses upon explicit teaching of four main reading strategies namely predicting, questioning, summarizing, and clarifying.

In a real classroom situation, in the RTR class, the topic of the reading exercise was introduced to the learners by using various techniques of teaching preferred by the researchers. The first paragraph was normally done by the teacher in a think-aloud process to provide a model to the learners on how they should use the strategies. After the modelling, the next paragraphs were assigned to the previously assigned groups of learners for them to practice the strategic in 
action. After carrying out the assigned process, the groups were instructed to consult and check their understanding of the text and the unknown vocabulary and grammatical points with their partners.

In a CIRC class, after the teacher introduced the topic and tried to relate it to the students' background knowledge through applying various strategies and techniques such as brainstorming and class discussion on the topic, students had the time to read the text silently and note down key vocabularies. Afterwards, they headed together with their groupmates to discuss unknown vocabularies and problematic areas of the text and answer related questions. Then, they engaged in some other activities such as paraphrasing and summarizing the topic. Finally, they involved in some wordrecognition activities.

\section{Statistical AnALysis AND Results}

To answer the research question justifiably, the raw scores were taken from the pre-test and post-test and were then submitted to the computer software Statistical Package of Social Sciences (SPSS version 20), using t-test. Then the researchers conducted independent samples t-test in order to compare the possible differences between the means of the two groups based on the gain scores from the post-tests.

The following tables illustrate the summary of t-tests. To compare the scores of the RTR and CIRC groups before the treatment, an independent samples t-test was conducted. As illustrated in Table 1, before the treatment there was no significant difference between the RTR group $(\mathrm{M}=16.96, \mathrm{SD}=3.95)$ and the CIRC group $[\mathrm{M}=16.31, \mathrm{SD}=2.97 ; \mathrm{t}$ $(102)=0.418$, p. $>.05]$.

TABLE I

THE INDEPENDENT SAMPLES T-TEST FOR THE RTR AND CIRC GROUPS (PRE-TEST)

\begin{tabular}{lllllll}
\hline Group & N & Mean & SD & df & t & Sig. \\
\hline RTR & 42 & 16.96 & 3.95 & 102 & .418 & 0.677 \\
\hline CIRC & 42 & 16.31 & 2.97 & & & \\
\hline
\end{tabular}

Table 1 above shows that there is no significant difference between the two groups of CIRC and RTR on their reading comprehension scores in the pretest. This confirms the results of the homogenization test that was conducted in the beginning of the procedure before the treatment began. Based on the results of this independent samples t-test on the pretest scores of reading comprehension, it can be concluded that there is no significant difference between the two groups in their reading comprehension at the outset of the study. The results of comparing the mean scores of the two groups in the posttest are presented in the following table.

TABLE II

THE INDEPENDENT SAMPLES T-TEST FOR THE RTR AND CIRC GROUPS (POST-TEST)

\begin{tabular}{llllll}
\hline Group & N & Mean & SD & df & t \\
\hline RTR & 42 & 36.69 & 3.50 & 102 & -25.87 \\
\hline CIRC & 42 & 17.87 & 3.91 & & \\
\hline *Sig. $p<.05$ & & & & &
\end{tabular}

In order to compare the scores of the RTR and CIRC groups after the treatment (post-test), the second independent samples t-test was conducted. As indicated in Table 2, there is a significant difference between the RTR group ( $\mathrm{M}=$ $36.69, \mathrm{SD}=3.50)$ and the CIRC group $(\mathrm{M}=17.87, \mathrm{SD}=3.91 ; \mathrm{t}(102)=-25.87, \mathrm{p}<.05)$. This final result shows that the mean score of the RTR group is more than the CIRC group after the treatment.

Therefore, it can be concluded that the participants who received RTR performed significantly better than those who received CIRC. Therefore, it can be concluded that reciprocal teaching, which consists of explicit teaching of four specific reading strategies, is proved to have a significantly better effect then CIRC on students' reading comprehension.

\section{DISCUSSION}

The purpose of this study was to investigate the difference between the effects of 'Reciprocal Teaching of Reading' and 'Cooperative Integrated Reading and Composition' on the reading comprehension of Iranian intermediate EFL learners. The results revealed that using RTR for teaching reading enhanced the participants' reading ability. The results corroborate the findings of previous research on the effectiveness of RTR (e.g., Rosenshine and Meister, 1994; Wisaijorn, 2003; Calderón, et al. 1998), and indicate that combined strategy instruction is an effective and useful way for improving EFL learners' reading ability. What the study adds to the literature is the effectiveness of RTR in comparison to CIRC.

In their study aimed at reviewing research on reciprocal teaching, Rosenshine and Meister (1994) conducted a meta-analysis of 16 quantitative studies in higher education focusing on reciprocal teaching. Their study revealed that reciprocal teaching was most effective for older students as well as those with poor comprehension skills. This finding is in line with the findings of the current study that found the effectiveness of RTR over CIRC.

Furthermore, what Wisaijorn (2003) found after examining the effects of RTR on reading comprehension in a quantitative/qualitative design with a pretest, a posttest, and a follow-up reading comprehension test, was that 
reciprocal teaching improved the students' reading ability. This finding is also another fact that RTR contributes to better reading comprehension gains in EFL learners when it is compared with other techniques of teaching reading comprehension.

There are also studies that have found results different from this study. One of these studies is that of Calderón, Hertz-Lazarowitz, and Slavin (1998) who evaluated the effects of bilingual CIRC on reading, writing and language achievements of Spanish and English in a Spanish bilingual program. They found that on the English test, third-graders scored significantly better than comparison students in reading but not in language. They then argue that third-graders who were in CIRC scored much better than RTR students on both scales. This study has found a different result from the current study.

A reasonable justification for such a finding could be related to the mechanism underlying RTR. In RTR knowledge is the result of negotiation among class participants, and learning is facilitated by the teacher's strategic guidance. Meanwhile, as the teacher provides further opportunity for all class participants to become actively engaged in strategic reading, students are encouraged to take a more active role in the course of shared reading. Furthermore, the mechanism underlying RTR increases students' task concentration and encourages groups of students to get critically engaged in the process of reading comprehension. This is because they need to construct meaning from the text and monitor the way they are doing that availing themselves of some effective strategies (Palincsar, Ransom, \& Derber, 1988). RTR engages all learners actively in the class procedure and, thus, reading the text and applying strategies become a joint responsibility shared by all class members. RTR encourages a teacher-student collaboration, and each student has the chance of becoming a dialogue leader. Such kind of situations helps to bring more meaning to the text at a cognitive and personal level.

To confirm the value of RTR for reading courses, Nation (2009) states that a balanced reading course should incorporate activities of other language skills because "learning to read is also helped by learning to write and learning through listening" (p. 5). Applying techniques that assist students understand each other better "can lead to greater facility with written language" (Mottley \& Telfer, 1995, p. 127), which contributes to their reading comprehension. Moreover, Lems, Miller, and Soro (2010) are of the stand that oracy is considered to be the foundation of literacy because as Richards (2008) states listening provides the comprehensible input that helps language learning and "triggers the further development of second language proficiency" (p. 3). Therefore, RTR is planned and implemented in a way that students' problems in understanding the meaning are addressed immediately and directly.

\section{CONCLUSION}

The result of the present study indicates that RTR benefits reading comprehension of intermediate EFL learners more significantly than CIRC. This is because whereas in CIRC settings students are involved in some minor activities which are not so much relevant to reading comprehension, in RTR settings students learn different aspects of reading comprehension strategies, including the ways to use them. This helps them develop their self-regulation for using reading strategies, which are of immense help for the construction of meaning or understanding. Teachers, however, should be cognizant of the fact that the more explicit the steps they follow in implementing RTR technique, the more clearly they can be distinguished with other CL techniques. Researchers are also suggested to investigate the effectiveness of some emerging CL methods like Competitive Team-Based Learning.

This study has some pedagogical implications for EFL teachers, syllabus designers and materials developers. For teachers, the results of this study can have the message of when they are to choose between CIRC and RTR techniques for teaching reading comprehension, which one they are suggested to prefer. In other words, in the Iranian context, as the results of data analysis suggest, RTR techniques can contribute better to reading comprehension gains than CIRC techniques. Therefore, EFL teacher are suggested to opt for more RTR techniques over other available techniques.

Syllabus designers are the other beneficiaries of the findings of the current research. This study helps them to design syllabi that favor more RTR techniques in the reading comprehension. Syllabi can be designed with more emphasis put on reciprocal teaching of reading over the other techniques. Furthermore, materials developers and those who are tasked with designing course books and learning materials are suggested to integrate more reciprocal techniques in their materials.

This study also suggests recommendations for further research. Further research in this area can be done by adding other variable to the scope of this research. Other variables that can be integrated here are gender, age and learning background. Also, culture can be a determining factor that may alter the results and yield different results compared to that of the current research. Furthermore, other research can be carried out on different techniques of teaching reading comprehension.

\section{REFERENCES}

[1] Alfassi, M. (2004). Reading to learn: Effects of combined strategy instruction on high school students. Journal of Educational Research, 97, 171-184.

[2] Anderson, N. J. (2013). ACTIVE Skills for Reading 2. Utah: Pearson Publishing.

[3] Calderón, M., Hertz-Lazarowitz, R., \& Slavin, R. (1998). Effects of bilingual cooperative integrated reading and composition on students making the transition from Spanish to English reading. The Elementary School Journal, 99(2), 153-165.

[4] Davis, B. G. (1999). Cooperative learning: Students working in small groups. Speaking of Teaching. Stanford University Newsletter on Teaching. 10(2), 1-24. 
[5] Durukan, E. (2011). Effects of Cooperative Integrated Reading and Composition(CIRC) technique on Reading-Writing Skills. Academic Journal, 6(1), 102-109.

[6] Farhadi, H. (1998). Constructing reading comprehension tests. Roshd ELT Journal, 13(49), 37-48.

[7] Gupta, M., \& Ahuja, J. (2014). Cooperative integrated reading composition (circ): impact on reading comprehension achievement in English among seventh graders. IMPACT: International Journal of Research in Humanities, Arts and Literature, 2(5), 37-46.

[8] Gurk, N. K., \& Mall-Amiri, B. (2016). The effect of cooperative learning techniques on intermediate Iranian EFL learners' reading comprehension and reading strategies. Journal of Studies in Education, 6(4), 33-59.

[9] Hadiwinarto, H., \& Novianti, N. (2015). Effects of Cooperative Integrated Reading and Composition Learning Model on the English Learning Skills. Journal of Education and Learning, 9(2), 117-124.

[10] Hosseini, S. M. H. (2010). Theoretical foundations of competitive team-based learning. Canadian Journal of English Language Teaching, 3(3): 229 - 243

[11] Hosseini, S. M. H. (2012). Beyond the present methods and approaches to ELT/Education: The crucial need for a radical reform. Tehran: Jungle Publications.

[12] Johnson, D. W., Johnson, R. T., and Smith, K. A. (1998). Active learning: Cooperative learning in the college classroom. Edina, MN: Interaction Book Company.

[13] Konpan, T. (2006). A comparison of reciprocal teaching technique and communicative teaching technique in developing Mattayom Suksa 4 Students'Reading Comprehension. Unpublished master dissertation, Srinakarinwirot University, Thailand.

[14] Lems, K., Miller, L. D., and Soro, T. M. (2010). Teaching reading to English language learners. U.S.: The Guilfrod Press.

[15] Momtaz, E. and Garner, M. (2010). Does collaborative learning improve EFL students' reading comprehension? Journal of Linguistics and Language Teaching, 1(1), 15-36.

[16] Mottley, R., and Telfer, R. (1995). Storytelling to promote emergent literacy: Prospective teachers' storytelling experiences and expectations. Retrieved July 19, 2018, from http://americanreadingforum.com/yearbook/yearbooks/97_yearbook/p df/11_mottley.pdf.

[17] Nation, I. S. P. (2009). Teaching ESL/EFL reading and writing. Routledge, Taylor \& Francis Group.

[18] Palincsar, A. S., Ransom, K., and Derber, S. (1988). Collaborative research and development of reciprocal teaching. Educational Leadership, 46, 37-40

[19] Palinscar, A. S., and Brown, A. L. (1985). Reciprocal teaching: Activities to promote reading with your mind. In T. L. Harris \& E. J. Cooper (Eds.), Reading thinking, and concept development: Strategies for the classroom (pp. 147-160). New York: The College Board.

[20] Richards, J. C. (2008). Teaching listening and speaking: From theory to practice. Cambridge: Cambridge University Press.

[21] Rosenshine, B., and Meister, C. (1994). Reciprocal teaching: A review of the research. Review of Educational Research, 64, $479-531$.

[22] Sittilert, W. (1994). Effects of cooperative integrated reading and composition (CIRC) on English reading comprehension and opinions about classroom atmosphere of mathayomsuksa five students. M.A. Dissertation, Chiangmai University.

[23] Slavin, R. E. (1995). Cooperative learning: Theory, research and practice. (2nd ed). Boston: Allyn and Bacon.

[24] Slavin, R. E. (2011). Instruction based on cooperative learning. In Mayer R, Alexander P, eds. Handbook of research on learning and instruction. New York, NY: Routledge, pp. 344-360.

[25] Wisaijorn, P. (2003). Teaching reading comprehension to Thai EFL students: Reciprocal Teaching Procedure. Unpublished thesis, University of Canberra, Canberra, Australia. Retrieved April 21, 2015, from http://adt.caul.edu.au/homesearch/find/?recordid=131086.

Zahra Kamdideh is a Ph.D. candidate in TEFL. She is an English teacher. Her current research interests are learning strategies, critical thinking, and translation studies.

Reza Vaseghi is currently an Assistant Professor of Applied Linguistics at the Islamic Azad University (IAU) in Amol, Iran. He started off his matriculation studies in ELT in 2002. He received his MA in TESL and PhD in Applied Linguistics from University Putra Malaysia (UPM) in 2010 and 2015, respectively. He has taught courses on Research Methodology, Language Testing and Assessment, Language Learning and Technology, Academic Writing, and Psycholinguistics at the MA and PhD levels over the last decade in Iran and Malaysia. He has supervised, co-supervised and examined a number of MA theses. Besides, he serves as an editor and a reviewer for various journals. He has also published journal articles and conference papers and presented at national and international levels. His academic areas of interest are research on a variety of topics in Applied Linguistics, Language Ass essment, Language Learning with Integrating Technology and Corpus Linguistics.

Saeedeh Talatifard is a Ph.D. candidate in TEFL, founder and manager of paidar English Institute, civil aviation supervisor, teaching English for 20 years, her current research interests are corrective feedback, critical thinking, learning strategies. 